\section{Editor's Report}

As always at this time we would like to briefly inform our readers of the Journal's development during the past year. The trend which has already been observed during the last two years, that is, a significant increase in the quantity of work submitted for publication, has continued. The number of manuscripts received (180) during 1986 represented a twenty-five percent increase on the previous year.

Accordingly, I would like to, once again, sincerely thank all authors for the interest they have shown in our Journal and to express my regret that, due to a limitation of page numbers by the Publishers, more than forty percent of the manuscripts could not be published. Of these, a not inconsiderable number were superior papers deserving the publication that, as a rule, on submission to other journals with comparable procedures of rigorous assessment, they happily received. Knowing from personal experience the effort required to prepare a manuscript for publication I am more than pleased that this has been the case. From another point of view it can be similarly stated that the efforts made by our reviewers, although they cannot of course always come to the same conclusions, ensure that only the newest and best information is offered. I sincerely hope that our readers have noticed that through this, so to speak, inevitable raising of our standards, we have had more to offer them. Fundamentally new findings, in particular, are far more to the fore than previously, although as before we have attempted, where possible, to accomodate a considerable part of the entire spectrum of new research within the confines of space imposed upon us. On the other hand, and in order to comply with the aforementioned shortage of space, we have been obliged to dispense with the laudations. This particularly saddens me because thereby a part of the history of Infectious Diseases Subspecialty, even though it may be only a small part, is lost. Moreover, most of our older colleagues on the Editorial Board have substantially helped to shape that history. To my great regret two events have been affected by this economy measure, namely the 70th birthday of $W$. Knapp (9.9.86) whose fundamental work on Yersinia is world famous, as well as the birthday of the pioneer of the investigation into the significance of Anaerobes in various infections, $S$. $M$. Finegold, who celebrated his 65th birthday on 12th August 1986.

Something which has fundamentally changed has been the number of supplements produced. In 1986, we produced four supplements, in addition to the Proceedings of the IXth International Congress of Infectious and Parasitic Diseases in Munich, parts of which were completely

\section{Ad-hoc-Workshop der Paul-Ehrlich-Gesellschaft für Chemotherapie}

,, Auswirkungen des neuen Arzneimittelgesetzes auf die Durchführung klinischer Prüfungen"4

Leitung: Prof. Dr. W. Stille revised. For 1987, seven supplements are already being prepared, three of these are not primarily concerned with chemotherapy but with particular infections.

At the last meeting of the Editorial Board the following changes were discussed:

INFECTION is one of the leading international journals with, inevitably, a European emphasis. In this form it can, in our opinion, be considered an absolutely essential supplement to the dominating American journals. This does not mean that we do not welcome authors from the States. The country of the successful pioneers of modern research into infection, their children and indeed grandchildren, has established a working, autonomous clinical infectiology and produces such a wealth of new publications that they are naturally welcome at any time. The fact that we are indeed a truly international journal can be shown by the diversity of lands from which our contributions come:

Scandinavia and FR Germany are represented by an equally large number of manuscripts. Then follow, in order of frequency: Italy, the U.S.A., Holland, France, Israel, Spain, GDR and Belgium. In addition, papers from the rest of Europe (the United Kingdom, Greece, Poland, Switzerland, Austria, Russia, Yugoslavia and Portugal) and, from further afield, Asia (China, Kuwait, Japan and Hong Kong), Africa (Ethiopia, Nigeria) and, in addition, Canada and Chile.

It is intended that in the future INFECTION will be published in English only apart from all-German supplements. With regard to the regular issues of the journal, from 1987 only English manuscripts will be included, although in the next issue some German papers which have already been accepted will appear. Also, papers originating from conferences or initiated by companies will be published in German or English, according to the wishes of the sponsors. Also, for the addenda to the regular editions and the supplements, though of course they will be edited, the rejection rate will inevitably be limited.

In the coming year it is intended, not least in view of the increasing number of contributions, to build up a European editorial staff. For various reasons this will, however, be a gradual process. We hope, in the year ahead, as far as is possible and with the cooperation of our authors, to be able to publish even better and more topical studies in which the clinical aspects of infectious diseases are foremost, naturally including specialist areas.

We wish all our readers not only a good, happy and above all peaceful New Year but also, not least on our behalf, that they will every now and then be able to prepare a contribution for publication in INFECTION.

W. Marget

Am Freitag, 20. Februar 1987, Beginn 10.30 Uhr, im Universitätsklinikum Frankfurt/Main, Haus 23, Hörsaal 2. 